\title{
The Effect of Initial Grain Size on Formability of AZ31B Magnesium Alloy during I-ECAP
}

\author{
Michal Gzyl ${ }^{1, a}$, Andrzej Rosochowski ${ }^{2, b}$, Lech Olejnik ${ }^{3, c}$, \\ Aleksey Reshetov ${ }^{1, d}$
}

\author{
${ }^{1}$ Advanced Forming Research Centre, University of Strathclyde, \\ 85 Inchinnan Drive, Renfrew PA4 9LJ, United Kingdom
}

\author{
${ }^{2}$ Design, Manufacture and Engineering Management, University of Strathclyde, \\ James Weir Building, 75 Montrose Street, Glasgow G1 1XJ, United Kingdom \\ ${ }^{3}$ Institute of Manufacturing Technology, Warsaw University of Technology, \\ ul. Narbutta 85, 02-524 Warsaw, Poland \\ amichal.gzyl@gmail.com, ba.rosochowski@strath.ac.uk, 9.olejnik@wip.pw.edu.pl, \\ daleksey.reshetov@strath.ac.uk
}

Keywords: magnesium alloys, equal channel angular pressing, ultrafine grained metals.

\begin{abstract}
The goal of this work was to investigate formability of AZ31B magnesium alloy during incremental equal channel angular pressing (I-ECAP). Square billets were processed using different routes of I-ECAP at temperatures varying from $125{ }^{\circ} \mathrm{C}$ to $250{ }^{\circ} \mathrm{C}$. The billets were obtained from commercially available coarse-grained, hot-extruded rod and fine-grained, hot-rolled plate. A strong influence of the initial microstructure on processing temperature was reported. Finegrained samples were successfully processed at $200{ }^{\circ} \mathrm{C}$, while coarse-grained ones must have been heated up to $250{ }^{\circ} \mathrm{C}$ to avoid fracture. A gradual temperature decrease with subsequent passes allowed successful pressing at $150{ }^{\circ} \mathrm{C}$. Processing using various routes of I-ECAP showed that a billet rotation before the last pass had strong influence on mechanical properties. The results of experiments were plotted on the diagram of allowable processing temperature for AZ31B. It was found that the relation between the minimum temperature in I-ECAP and the initial grain size could be described by a logarithmic equation.
\end{abstract}

\section{Introduction}

Equal channel angular pressing (ECAP) [1] is a very effective method of improving strength and ductility of magnesium alloys [2]. In this process, a billet is pressed through a die with two intersecting channels of the same dimensions; usually the angle between the channels ranges from $90^{\circ}$ to $135^{\circ}$. The pressing procedure can be repeated, which enables obtaining a very large plastic strain and, as a consequence, a significant grain refinement. Different processing routes can be realised by rotating a billet around its axis between consecutive passes. The most common are routes $\mathrm{A}, \mathrm{B}_{\mathrm{C}}$ and $\mathrm{C}$, which are equivalent to rotation by $0^{\circ}, 90^{\circ}$ and $180^{\circ}$. AZ31 magnesium alloy subjected to ECAP usually exhibits enhanced room temperature ductility and superplastic properties at temperatures lower than a coarse-grained material [3].

The main drawback of the conventional ECAP is a limitation of the billet's length due to a high force required to press a long bar through the channel. In order to solve this problem, incremental ECAP (I-ECAP) was proposed by Rosochowski and Olejnik [4]. In I-ECAP, the stages of material feeding and plastic deformation are separated, which reduces the feeding force significantly. The tool configuration consists of a punch working in a reciprocating manner and a die feeding the material in incremental steps. As long as the feeding stroke is appropriately small, the subsequent shear zones overlap, giving a uniform strain distribution along the billet. I-ECAP can be used for processing long bars [5], plates [6] and sheets [7].

ECAP and I-ECAP of magnesium alloys are typically conducted at an elevated temperature to avoid fracture. However, a lower processing temperature enables obtaining a finer microstructure since the grain refinement process is believed to be controlled by dynamic recrystallization $[3,8]$. 
AZ31, which is the most common magnesium wrought alloy, is usually processed at $250{ }^{\circ} \mathrm{C}$ or 200 ${ }^{\circ} \mathrm{C}$. However, it is possible to reduce this temperature to $150{ }^{\circ} \mathrm{C}$ when a very low ram speed is applied [9]. The effects of temperature and strain rate on formability of AZ31B subjected to ECAP were already investigated in [10]. It was shown that the material was very sensitive to variation in strain rate and increasing pressing speed led to fracture by segmentation. The goal of the current research was to investigate the effects of the initial microstructure and process temperature on formability of AZ31B in I-ECAP.

\section{Material}

A commercially available AZ31B magnesium alloy was used in the current study. The material was supplied either in the form of hot-extruded round rods with the diameter of $16.8 \mathrm{~mm}$ or hotrolled $20 \mathrm{~mm}$ thick plate. The initial microstructure of the rod was heterogeneous with coarse grains $(\sim 80 \mu \mathrm{m})$ surrounded by colonies of small grains $(\sim 10 \mu \mathrm{m})$, as shown in Fig. 1a. The microstructural image was taken on the plane along extrusion direction (ED). The occurrence of small grain colonies was attributed to dynamic recrystallization taking place during extrusion at elevated temperatures. Some samples were annealed at $300{ }^{\circ} \mathrm{C}$ for 8 hours prior to processing, which resulted in microstructure homogenisation $(\sim 60 \mu \mathrm{m})$. As shown in Fig. 1b, microstructure of the hot-rolled plate, with the average grain size of $\sim 8 \mu \mathrm{m}$, was much finer compared to the rods. However, bands of small grains $(\sim 3 \mu \mathrm{m})$ were revealed along rolling direction (RD). Tensile tests carried out along ED and RD showed that the room temperature ductility of the plate was twice as high as that of the rod; the stress-strain curves are displayed in Fig. 1c.

a)

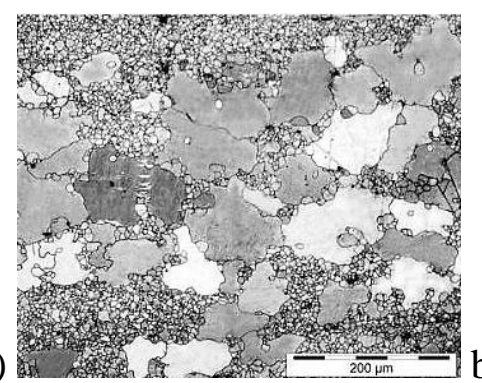

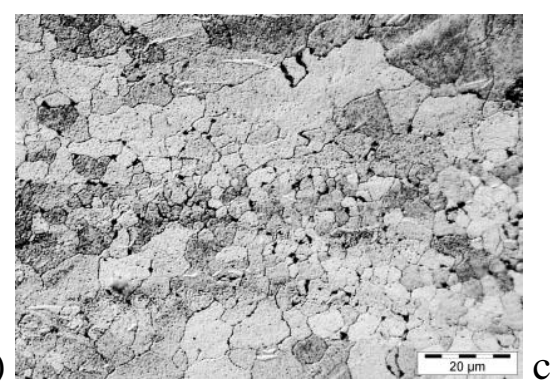

c)

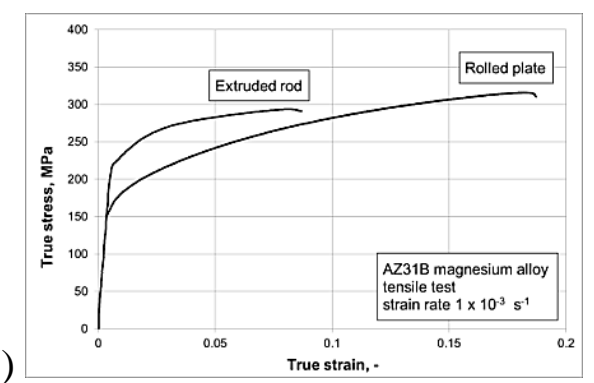

Fig. 1. Initial microstructures of extruded rod (a), rolled plate (b) and their mechanical properties (c); extrusion and rolling directions are horizontal.

\section{Experimental procedure}

Mechanical testing and microstructural characterization of the as-received materials were conducted prior to processing. Tensile tests were carried out at room temperature with the initial strain rate $1 \times 10^{-3} \mathrm{~s}^{-1}$. Instron 5969 testing machine with the maximum load capacity $50 \mathrm{kN}$ was used. Flat specimens, with thickness equal to $2 \mathrm{~mm}$ and dimensions of the gauge section $2.5 \mathrm{~mm} \times$ $14 \mathrm{~mm}$, were cut out along ED and RD using wire electrical discharge machining. Olympus GX51 optical microscope was used to perform microstructural characterization. The sample preparation procedure included grinding, polishing and etching. Samples were ground using SiC paper P1200. Then, they were mechanically polished using polycrystalline suspensions with particle sizes 9 and 1 $\mu \mathrm{m}$. Colloidal silica was used for the final polishing. Afterwards, specimens were etched using acetic picral in order to reveal grain boundaries. The mean grain size was measured by a linear intercept method.

Square bars with lengths varying from $60 \mathrm{~mm}$ to $120 \mathrm{~mm}$ and cross-sections $10 \times 10 \mathrm{~mm}^{2}$ were machined from the supplied rod and plate. A double-billet variant of I-ECAP [11], with $90^{\circ}$ angle between channels, was realised using a $1 \mathrm{MN}$ hydraulic servo press; the schematic illustration of the process is shown in Fig. 2. The billets were fed using a motor driven screw jack whose action was synchronized with the reciprocating movement of the punch. The feeding stroke was equal to 0.2 $\mathrm{mm}$. The punch movement followed an externally generated sine waveform with frequency $0.5 \mathrm{~Hz}$ 
and peak-to-peak amplitude of $2 \mathrm{~mm}$. The heating of billets was realised by holding them for 15 minutes prior to processing in the preheated die. The die temperature during processing was kept constant within $\pm 2{ }^{\circ} \mathrm{C}$, based on the readings obtained from a thermocouple located near the deformation zone. A siliconbased ceramic phase composite coating was applied on the billet surface prior to lubrication with conventional molybdenum disulphide $\left(\mathrm{MoS}_{2}\right)$ [12].

Experiments were carried out in order to find the lowest possible processing temperature and investigate the influence of the initial microstructure and temperature on formability of

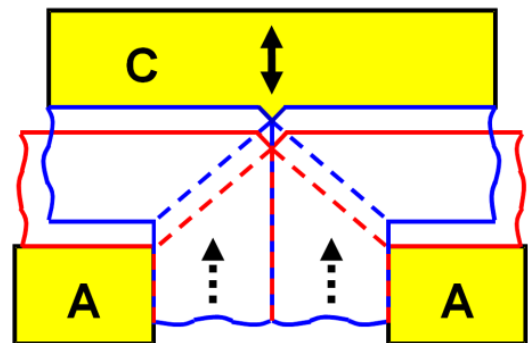

Input channel

Fig. 2. Schematic illustration of I-ECAP. AZ31B magnesium alloy during I-ECAP. Billets were processed by different routes, $\mathrm{A}, \mathrm{B}_{\mathrm{C}}$ and $\mathrm{C}$, at temperatures varying from $125{ }^{\circ} \mathrm{C}$ to $250{ }^{\circ} \mathrm{C}$. Four to six passes were planned for each experimental variant. However, in some cases, fracture occurred before reaching the intended number of passes. Table 1 shows the experimental plan and the results of conducted experiments.

Table 1. Details of I-ECAP experiments

\begin{tabular}{|c|c|c|c|c|c|c|}
\hline $\begin{array}{l}\text { Sample } \\
\text { no. }\end{array}$ & Material & $\begin{array}{c}\text { No. } \\
\text { passes }\end{array}$ & Temperature & Route & Result & Comments \\
\hline 1 & Extruded rod & 1 & $200^{\circ} \mathrm{C}$ & $\mathrm{n} / \mathrm{a}$ & $x$ & Damaged \\
\hline 2 & $\begin{array}{l}\text { Extruded rod } \\
(\text { annealed })\end{array}$ & 1 & $200^{\circ} \mathrm{C}$ & $\mathrm{n} / \mathrm{a}$ & $x$ & $\begin{array}{c}\text { Damaged } \\
{ }^{*} \text { Annealed } 8 \text { hours at } 300^{\circ} \mathrm{C}\end{array}$ \\
\hline 3 & Extruded rod & 4 & $4 \times 250^{\circ} \mathrm{C}$ & $A$ & $\checkmark$ & \\
\hline 4 & Extruded rod & 4 & $4 \times 250^{\circ} \mathrm{C}$ & $\mathrm{B}_{\mathrm{C}}$ & $\checkmark$ & \\
\hline 5 & Extruded rod & 4 & $4 \times 250^{\circ} \mathrm{C}$ & $\mathrm{C}$ & $\checkmark$ & \\
\hline 6 & Extruded rod & 5 & $5 \times 250^{\circ} \mathrm{C}$ & $4 \times B_{C}+A$ & $\checkmark$ & \\
\hline 7 & Extruded rod & 3 & $2 \times 250^{\circ} \mathrm{C}+1 \times 200^{\circ} \mathrm{C}$ & $\mathrm{B}_{\mathrm{C}}$ & $x$ & Damaged \\
\hline 8 & Extruded rod & 3 & $\begin{array}{c}2 \times 250^{\circ} \mathrm{C}+\text { annealing }^{*} \\
+1 \times 200^{\circ} \mathrm{C}\end{array}$ & $\mathrm{B}_{\mathrm{C}}$ & $\sqrt{ } / x$ & $\begin{array}{c}\text { Minor, random cracks } \\
{ }^{*} \text { Annealed } 8 \text { hours at } 300^{\circ} \mathrm{C}\end{array}$ \\
\hline 9 & Extruded rod & 6 & $4 \times 250^{\circ} \mathrm{C}+2 \times 200^{\circ} \mathrm{C}$ & $A$ & $\checkmark$ & \\
\hline 10 & Extruded rod & 6 & $4 \times 250^{\circ} \mathrm{C}+2 \times 200^{\circ} \mathrm{C}$ & $\mathrm{B}_{\mathrm{C}}$ & $\sqrt{ } / x$ & Minor, random cracks \\
\hline 11 & Extruded rod & 6 & $4 \times 250^{\circ} \mathrm{C}+2 \times 200^{\circ} \mathrm{C}$ & C & $x$ & Damaged \\
\hline 12 & Rolled plate & 1 & $175^{\circ} \mathrm{C}$ & $\mathrm{n} / \mathrm{a}$ & $x$ & $\begin{array}{l}\text { Damaged, fracture lines along } \\
\text { rolling direction }\end{array}$ \\
\hline 13 & Rolled plate & 4 & $4 \times 200^{\circ} \mathrm{C}$ & $\mathrm{C}$ & $\checkmark$ & \\
\hline 14 & Rolled plate & 4 & $\begin{aligned} & 200^{\circ} \mathrm{C}+175^{\circ} \mathrm{C} \\
+ & 150^{\circ} \mathrm{C}+150^{\circ} \mathrm{C}\end{aligned}$ & A & $\checkmark$ & \\
\hline 15 & Rolled plate & 4 & $\begin{aligned} & 200^{\circ} \mathrm{C}+175^{\circ} \mathrm{C} \\
+ & 150^{\circ} \mathrm{C}+125^{\circ} \mathrm{C}\end{aligned}$ & $A$ & $x$ & Damaged \\
\hline
\end{tabular}




\section{Results and discussion}

I-ECAP of bars machined from the extruded rod. Square bars machined from the hotextruded rod of AZ31B were subjected to I-ECAP at $200{ }^{\circ} \mathrm{C}$ but the obtained billets were completely damaged (sample 1 in Table 1). Therefore, annealing for 8 hours at $300{ }^{\circ} \mathrm{C}$ was introduced prior to processing in order to homogenise the microstructure (sample 2). However, the applied heat treatment did not improve formability so the final result was the same as for the billets without the annealing step (Fig. 3). The processing temperature was increased to $250{ }^{\circ} \mathrm{C}$ in the next set of experiments and four passes of I-ECAP were successfully completed using routes $\mathrm{A}, \mathrm{B}_{\mathrm{C}}$ and $\mathrm{C}$, which are referred to in Table 1 as samples 3, 4 and 5, respectively. The influence of the processing route on mechanical properties has been already reported in [12-13].

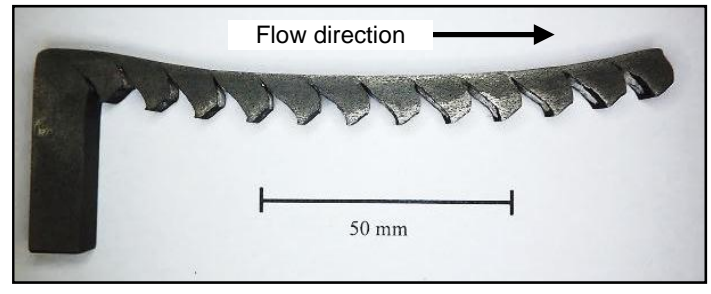

Fig. 3. Sample no. 2 after annealing and I-ECAP at $200{ }^{\circ} \mathrm{C}$.

Since a finer microstructure can be produced in magnesium alloys at lower temperatures, further attempts were made to avoid fracture at $200{ }^{\circ} \mathrm{C}$. The idea was based on the gradual temperature decrease with subsequent passes of I-ECAP. Sample 7 was processed by two passes at $250{ }^{\circ} \mathrm{C}$ and the third pass was conducted at $200{ }^{\circ} \mathrm{C}$ (following route $\mathrm{B}_{\mathrm{C}}$ ), but large cracks were observed on the billets, as displayed in Fig. 4. Therefore, an additional annealing step ( 8 hours at $300{ }^{\circ} \mathrm{C}$ ) was introduced after two passes of I-ECAP at $250{ }^{\circ} \mathrm{C}$, which should have resulted in a reduction of internal stresses with a concurrent microstructure homogenisation. Although the grain size was probably finer than in the case of sample 2, small cracks were still observed on the billet surface so this processing route was classified as unsuccessful as well.
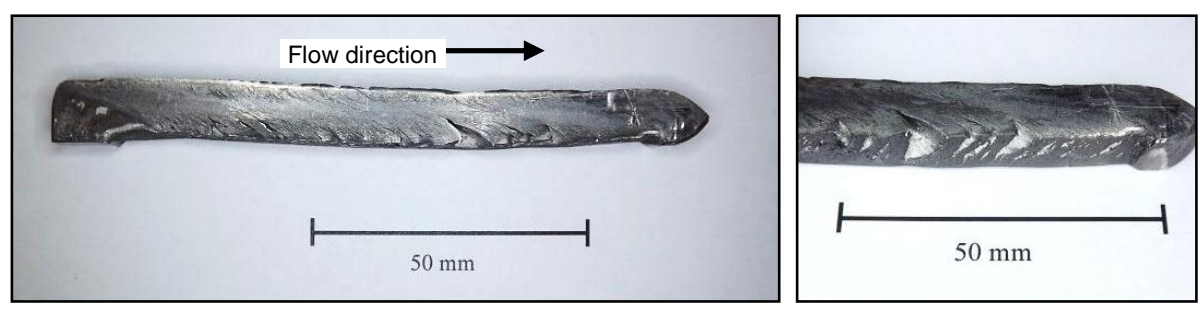

Fig. 4. Billet processed by two passes at $250{ }^{\circ} \mathrm{C}$ and one pass at $200{ }^{\circ} \mathrm{C}$ by route $\mathrm{B}_{\mathrm{C}}$ (sample 7 ).

Samples 9-11 followed 4 passes of I-ECAP at $250{ }^{\circ} \mathrm{C}$ to reduce the average grain size to $\sim 6 \mu \mathrm{m}$ [12]. Then, bars were subjected to another two passes at $200{ }^{\circ} \mathrm{C}$. The obtained results were surprising as billets processed by route $A$ were not fractured while those processed using route $B_{C}$ exhibited minor cracking in the corner where the material did not fill the exit channel completely. Moreover, some billets subjected to route $\mathrm{B}_{\mathrm{C}}$ were completely free from surface cracks even though the same parameters were used. Sample 11, which was pressed by route $\mathrm{C}$, was massively damaged after I-ECAP, as shown in Fig. 5.

The conducted experiments showed that hot-extruded $\operatorname{rod}$ of AZ31B can be processed by I-ECAP at $250{ }^{\circ} \mathrm{C}$ without fracture occurrence. Temperature reduction to $200{ }^{\circ} \mathrm{C}$ was possible only after four passes at $250{ }^{\circ} \mathrm{C}$, which resulted in grain refinement to $\sim 6 \mu \mathrm{m}$. Moreover, route $\mathrm{A}$ proved to be less prone to fracture than routes $B_{C}$ and $C$.

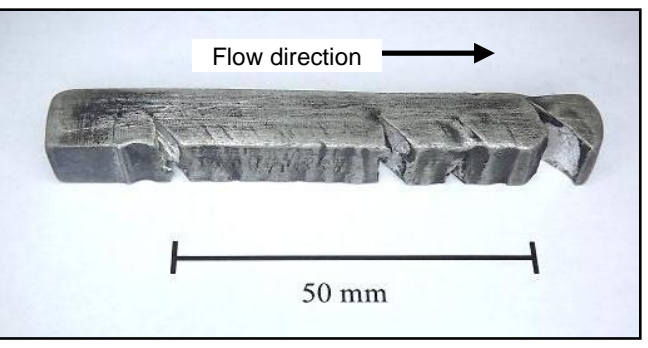

Fig. 5. Massively damaged sample 11 after 4 passes at $250{ }^{\circ} \mathrm{C}$ and two passes at 200 by route $C$. 
I-ECAP of bars machined from the hot-rolled plate. It was shown for the extruded rods that a finer initial microstructure enabled lowering temperature of I-ECAP. Therefore, another set of experiments was conducted using square bars machined from the hot-rolled plate, which exhibited finer grain structure and greater ductility compared with the hotextruded rods. The first pass of I-ECAP was conducted at $175{ }^{\circ} \mathrm{C}$, but long fracture lines, shown in Fig. 6, were revealed nearly parallel to the billet axis. They could be arising from the bands of small grains observed in the initial sample along RD. Sample 12 was subjected to four passes of I-ECAP at $200{ }^{\circ} \mathrm{C}$. Route $\mathrm{C}$ was chosen for this variant as it has been already shown to be the most prone to fracture. In contrast to the results obtained for sample 11, the processed bars had good surface quality, which proved that finer grain

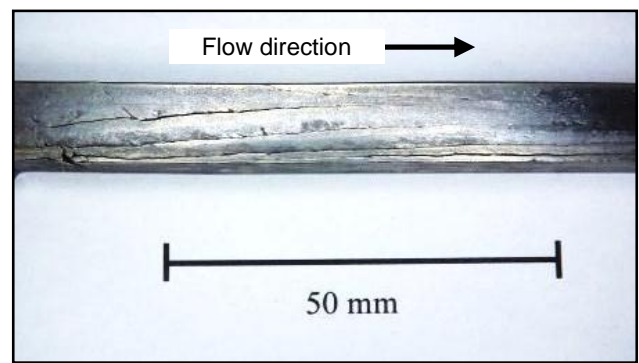

Fig. 6. Fracture mechanism in rolled sample subjected to I-ECAP at $175{ }^{\circ} \mathrm{C}$. structure enables reducing temperature of I-ECAP.

The gradual temperature decrease approach was used for samples 14 and 15 . In the case of sample 14 , temperature was reduced by $25^{\circ} \mathrm{C}$ in two steps from initial $200{ }^{\circ} \mathrm{C}$ to $150{ }^{\circ} \mathrm{C}$; the fourth pass was conducted again at $150{ }^{\circ} \mathrm{C}$ to homogenise the microstructure. Route A was chosen as it has been already shown for sample 7 to be the least prone to fracture. As this approach turned out to be successful, further temperature reduction in the last pass was attempted for sample 15 but massive damage was observed at $125{ }^{\circ} \mathrm{C}$. The billets after fourth pass of I-ECAP at $150{ }^{\circ} \mathrm{C}$ and $125^{\circ} \mathrm{C}$ are shown in Fig. 7.
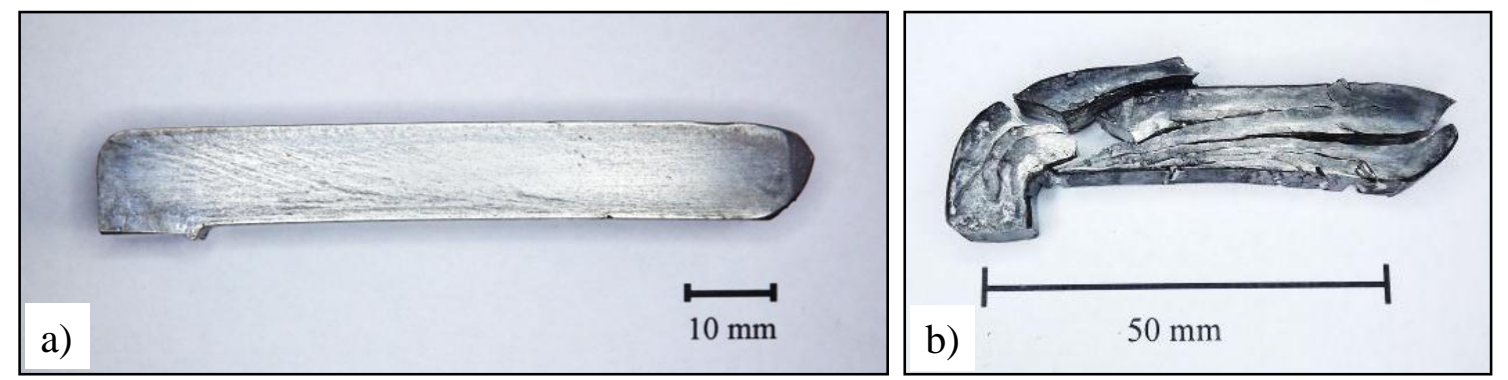

Fig. 7. Successful sample 14 after fourth pass of I-ECAP at $150{ }^{\circ} \mathrm{C}$ (a) and severely damaged sample 15 after reducing temperature to $125^{\circ} \mathrm{C}(\mathrm{b})$.

In some cases, fracture was observed only at the beginning or at the end of billet, when a gradual temperature reduction was applied (Fig. 8a). It could be attributed to a low deformation level occurring in those zones during I-ECAP. The FE simulation results, displayed in Figure $8 \mathrm{~b}$, showed that plastic strain in the non-deformed regions was less than 0.15 . Therefore, the grain size could not be refined significantly in those regions and they acted often as fracture initiation sites. Such end-effects were not revealed when temperature was kept constant for all passes.
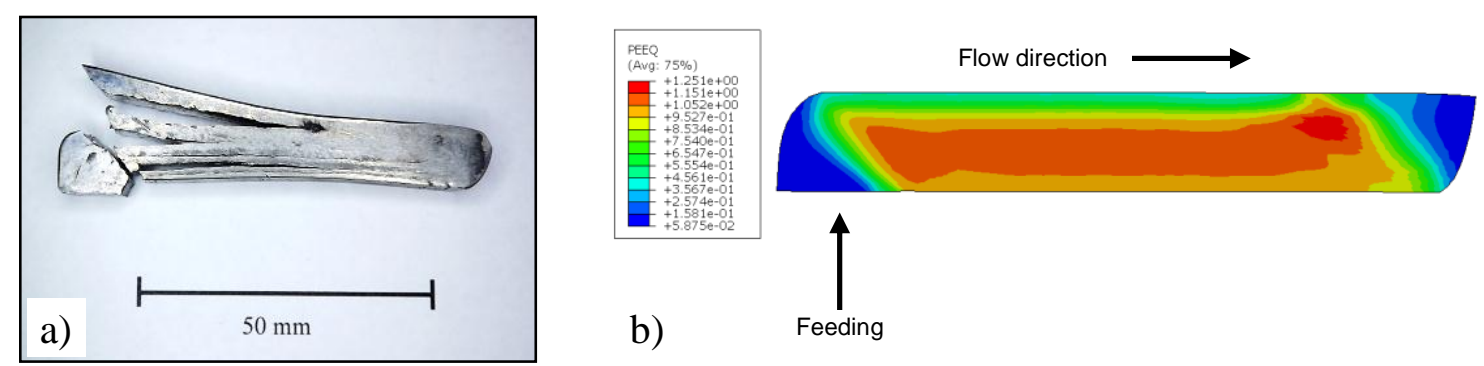

Fig. 8. Shear fracture localised at the end of sample (a) and plastic strain field from FE simulation indicating non-deformed zones after I-ECAP (b). 
Shapes of undamaged billets. Apart from the influence of the processing routes on the mechanical properties reported in [12], significant differences in the shapes of billets made of hotextruded bars and subjected to I-ECAP using different routes were observed. The material completely filled the exit channel when billets were processed using route $\mathrm{A}$ while rotation by $180^{\circ}$ and $90^{\circ}$ resulted in an incomplete filling of the exit channel and, as a consequence, asymmetrical shapes of the billets (Fig. 9). The height of the billet subjected to route $\mathrm{C}$ was $9 \mathrm{~mm}$, compared with $10 \mathrm{~mm}$ obtained using route $\mathrm{A}$. An asymmetrical billet shape was also observed for sample 4 , which was rotated by $90^{\circ}$ around its axis after each pass. Its height was non-uniform along cross-section and was varying from 7.5 to $9 \mathrm{~mm}$. This effect was attributed to the inhomogeneous strain rate sensitivity of the material arising from

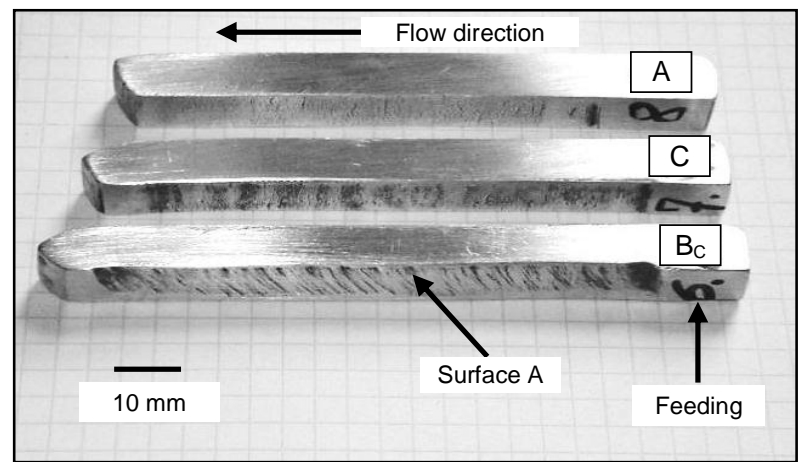

Fig. 9. Billets processed by I-ECAP at $250{ }^{\circ} \mathrm{C}$ using different routes. The arrow indicates surface A which is in contact with die A, shown in Fig. 2. the non-uniform strain distribution [13].

In order to reduce the asymmetry of a billet processed by route $\mathrm{B}_{\mathrm{C}}$ (sample 4), the combination of routes $\mathrm{B}_{\mathrm{C}}$ and $\mathrm{A}$ was used (sample 6). First, the billet was subjected to four passes at $250{ }^{\circ} \mathrm{C}$ using route $\mathrm{B}_{\mathrm{C}}$. Tensile tests showed that true strain at fracture was increased from $\sim 0.08$ to $\sim 0.23$. Additional pressing, without any rotation after fourth pass, was conducted at the same temperature. The gap observed in sample 4 was reduced from 2.5 to 0.2 as shown in Fig. 10a. However, true strain at fracture was decreased for sample 6 from $\sim 0.23$ to $\sim 0.11$. It is apparent from Fig. 10b, that mechanical properties of the sample processed by four passes using route $\mathrm{B}_{\mathrm{C}}$ with additional pass without any rotation were very similar to the sample after four passes with route A. It clearly shows that the last rotation has the strongest influence on the mechanical properties of the AZ31B magnesium alloy subjected to I-ECAP.
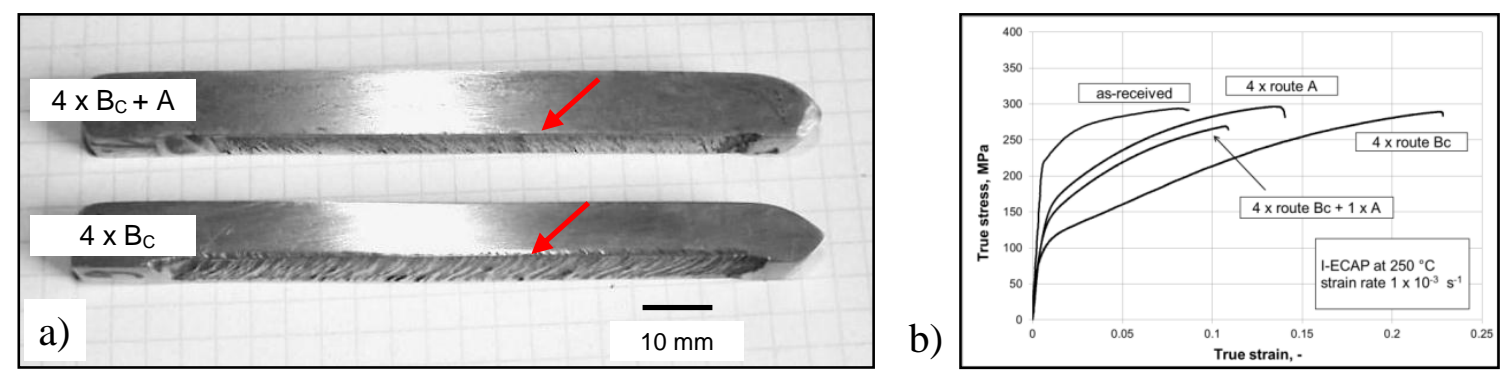

Fig. 10. (a) Billet processed by four passes using route $\mathrm{B}_{\mathrm{C}}$ (lower) and with one additional pass without any rotation (upper); arrows indicate the gap between the lower surface of the billets and the die A (as marked in Fig. 2). Tensile strain-stress curves for billets subjected to different sequences of rotations (b).

Processing window for I-ECAP of AZ31B. The results of the conducted experiments were plotted on the diagram shown in Fig. 11. It is concluded that the initial grain size should be less than $10 \mu \mathrm{m}$ to conduct I-ECAP at $200{ }^{\circ} \mathrm{C}$, and temperature should be increased to $250{ }^{\circ} \mathrm{C}$ for coarsegrained samples. The lowest temperature of successful I-ECAP in the current study was $150{ }^{\circ} \mathrm{C}$ and it was achieved by earlier processing by two passes at $200{ }^{\circ} \mathrm{C}$ and one pass at $175^{\circ} \mathrm{C}$. The diagram was used to find a relation between the initial average grain size and the lowest allowable temperature. It was noticed that the best fitting between grain size and temperature can be obtained by using a logarithmic equation expressed as:

$T \geq A * \ln (d)+B$ 
where: $T$ - allowable temperature in I-ECAP, $d$ - average initial grain size, $A, B$ - empirical coefficients obtained from experiments, which are: $A=27.03$ and $B=140.72$.

The curve defined by equation (1) determines the window of allowable processing parameters for I-ECAP with strain rate $\sim 0.5 \mathrm{~s}^{-1}$. The experimental results were compared with data obtained for conventional ECAP [2-3, 9]. Most of the results are consistent with the findings of the current research. However, ECAP with the very low strain rate $\left(\sim 0.015 \mathrm{~s}^{-1}\right)$ was carried out without the occurrence of fracture at temperature as low as $150{ }^{\circ} \mathrm{C}$ with the initial grain size $\sim 9.7 \mu \mathrm{m}$ [9]. It shows that the curve defined by equation (1) could be moved down on the diagram for the strain rates lower than $0.5 \mathrm{~s}^{-1}$.

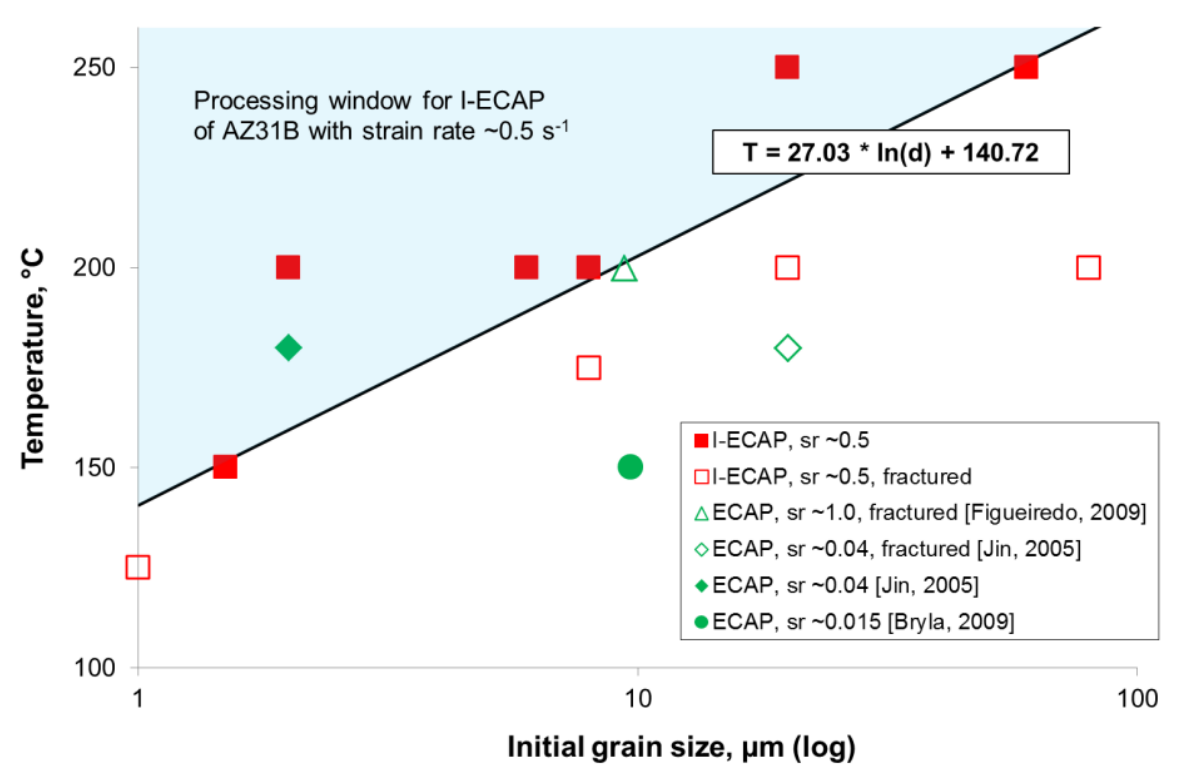

Fig. 11. Diagram of allowable processing temperature obtained from I-ECAP experiments of AZ31B with strain rate $\sim 0.5 \mathrm{~s}^{-1}$. Experimental results of ECAP derived from literature are plotted for comparison. Filled marks represent successful pressing, while hollow marks indicate fracture. In the chart legend, ' $\mathrm{sr}$ ' is strain rate expressed in $\mathrm{s}^{-1}$, ' $\mathrm{T}$ ' is temperature and ' $\mathrm{d}$ ' is the average grain size.

\section{Conclusions}

The goal of the current work was to investigate formability of AZ31B magnesium alloy during IECAP. The strong influence of the initial microstructure on the processing temperature was reported. Fine-grained samples $(\sim 8 \mu \mathrm{m})$ were successfully pressed at $200{ }^{\circ} \mathrm{C}$, while coarse-grained ones $(\sim 60 \mu \mathrm{m})$ must have been heated up to $250{ }^{\circ} \mathrm{C}$ to avoid fracture. The procedure of gradual temperature decrease allowed conducting of two final passes at $150{ }^{\circ} \mathrm{C}$ but further lowering of temperature resulted in fracture of billets.

It was shown that the procedure of gradual temperature decrease required cutting off the ends of billets. FE simulation showed that plastic strains in those zones were much smaller than in the rest of sample. Therefore, the grain size was not refined enough to allow further processing at lower temperature. Fracture was not observed in the investigated zones when temperature was kept constant in all passes of I-ECAP.

Processing by different routes showed that route $\mathrm{C}$ is the most prone to fracture, while route $\mathrm{A}$ enabled lowering temperature to $150{ }^{\circ} \mathrm{C}$. Distortion of the billet shape was reported for the samples processed by four passes of I-ECAP using route $\mathrm{B}_{\mathrm{C}}$. This effect could be significantly suppressed by subsequent pressing without any rotation. However, it was also shown that mechanical properties are strongly dependant on a billet rotation before the last pass. 
The results of I-ECAP experiments conducted at temperatures varying from 125 to $250{ }^{\circ} \mathrm{C}$ were used to draw a diagram of allowable processing temperature for AZ31B magnesium alloy deformed at a strain rate of $0.5 \mathrm{~s}^{-1}$. It was found that a linear relation between the minimum allowable temperature and the logarithm of the initial grain size existed and that lowering the strain rate would shift that relation towards lower temperatures.

\section{Acknowledgements}

Financial support from Carpenter Technology Corporation is kindly acknowledged. Part of this research was supported by the Engineering and Physical Sciences Research Council [grant number EP/G03477X/1].

\section{References}

[1] V.M. Segal, V.I. Reznikov, A.E. Drobyshevskiy and V.I. Kopylov, Plastic metal working by simple shear, Russian Metallurgy 1 (1981) 115-123 (Engl. Transl.).

[2] L. Jin, D. Lin, D. Mao, X. Zeng, B. Chen, W. Ding, Microstructure evolution of AZ31 Mg alloy during equal channel angular extrusion, Materials Science and Engineering A 423 (2005) 247252.

[3] R.B. Figueiredo, T.G. Langdon, Principles of grain refinement and superplastic flow in magnesium alloys processed by ECAP, Materials Science and Engineering A, 501 (2009) 105-14.

[4] A. Rosochowski, L. Olejnik, FEM simulation of incremental shear, in: E. Cueto, F. Chinesta, Proceedings of the 10th International Conference on Material Forming, Esaform 2007, April 18-20, 2007, Zaragoza, Spain, American Institute of Physics 907 (2007) 653-658.

[5] A. Rosochowski, L. Olejnik, Incremental equal channel angular pressing for grain refinement, Materials Science Forum 674 (2011) 19-28.

[6] L. Olejnik, A. Rosochowski, M. Richert, Incremental ECAP of plates, Materials Science Forum, 584-586 (2008) 108-13.

[7] A. Rosochowski, M. Rosochowska, L. Olejnik, B. Verlinden, Incremental equal channel angular pressing of sheets, Steel Research International 81 (2010) 470-73.

[8] M. Gzyl, A. Rosochowski, A. Milenin, L. Olejnik, Modelling microstructure evolution during equal channel angular pressing of magnesium alloys using cellular automata finite element method, Computer Methods in Materials Science 13 (2013) 357-63.

[9] K. Bryla, J. Dutkiewicz, P. Malczewski, Grain refinement in AZ31 alloy processed by equal channel angular pressing, Archives of Materials Science and Engineering 40 (2009) 17-22.

[10] F. Kang, J.T. Wang, Y. Peng, Deformation and fracture during equal channel angular pressing of AZ31 magnesium alloy, Materials Science and Engineering A 487 (2008) 68-73.

[11] A. Rosochowski, L. Olejnik, M. Richert, Double-billet incremental ECAP, Materials Science Forum 584-586 (2008) 139-44.

[12] M. Gzyl, A. Rosochowski, R. Pesci, L. Olejnik, E. Yakushina, P. Wood, Mechanical properties and microstructure of AZ31B magnesium alloy processed by I-ECAP, Metallurgical and Materials Transactions A (2013) DOI: 0.1007/s11661-013-2094-Z (in press).

[13] M. Gzyl, A. Rosochowski, E. Yakushina, P. Wood, L. Olejnik, Route effects in I-ECAP of AZ31B magnesium alloy, Key Engineering Materials, $554-557$ (2013) 876-84. 